\title{
Influence of X-rays on the thermal properties of poly(methyl methacrylate)
}

\author{
Małgorzata Gil, ${ }^{* 1}$ Grzegorz Wójcik, ${ }_{1}^{1}$ Kamil Szewczyk, ${ }^{2}$ Janusz Pędzisz, ${ }^{1}$ Jarosław Kopeć, ${ }^{1}$ Lidia Czyżewska, ${ }^{1}$ \\ Aleksander Walewski, ${ }^{1}$ Andrzej Gorgol, ${ }^{1}$ Wiesław Podkościelny, ${ }^{1}$ Paweł Mergo ${ }^{1}$ \\ ${ }^{1}$ Laboratory of Optical Fiber Technology, Maria Curie-Sklodowska University, Pl. Sklodowskiej 3, 20-031 Lublin, \\ Poland \\ ${ }^{2}$ Central Laboratory for Radiological Protection, Department of Radiation Monitoring and Calibration, \\ Konwaliowa Str. 7, 03-194 Warsaw
}

Received December 11, 2014; accepted December 29, 2024; published December 31, 2014

\begin{abstract}
The aim of this work was to determine the influence of Xrays on the thermal properties of poly(methyl methacrylate), typically used as a basic material in the technology of polymer optical fibers. The thermal properties of the investigated polymers were evaluated using thermogravimetric analysis (TGA).
\end{abstract}

Optical fibers used in sensors, provide a medium that allows measurement of a radiation dose in real time. They offer many advantages over conventional methods. An important advantage is their resistance to electromagnetic interference and chemical impact. At the same time, they can be placed at a large distance from an electronic control system, which makes particularly useful in areas with high levels of radiation [1].

Depending on the radiation type and dose, the properties of polymer optical fibers may be changed. The most obvious effect is an increase in attenuation and a change in their physicochemical and mechanical properties [2-4]. Radiation effects depend not only on the length of a transmitted wave but also on the type of material from which the fiber is made. The fibers, which have low attenuation, are more sensitive to radiation. It may cause different effects, particularly it may result in degradation of the fiber or its crosslinking, which usually adversely affects transmission in the fiber. The effect of ionizing radiation is reduced in the case of compounds, which in their structure contain aromatic groups and double bonds [5-6]. This work is focused on identifying the radiological impact on commercially available poly(methyl methacrylate) (PMMA). Most of the papers relating to Xrays, deal with their impact on optical properties of PMMA optical fibers. Our work concerns the radiological impact on thermal properties of PMMA. This is especially important because it determines the thermal strength of PMMA optical fibers.

Three samples of commercially available PMMA (PLASTIC GROUP) were analyzed. All samples were subjected to X-ray radiation for 4 hours. Three doses of

\footnotetext{
*E-mail: malgorzata.gil5@gmail.com
}

radiation were applied: 243Gy, 419.7Gy and 493.1Gy (Table 1).

Table 1. The conditions and results of X-rays radiation.

\begin{tabular}{|l|l|l|l|}
\hline & Sample no. 1 & Sample no. 2 & Sample no. 3 \\
\hline $\begin{array}{l}\text { voltage and } \\
\text { incandescence current } \\
\text { of X-ray tube }\end{array}$ & $50 \mathrm{kV}$, & $100 \mathrm{kV}$, & $150 \mathrm{kV}$, \\
\hline exposure time $[\mathrm{h}]$ & 4 & $10 \mathrm{~mA}$ & $10 \mathrm{~mA}$ \\
\hline Kerma in the air [Gy] & 243 & 4 & 4 \\
\hline
\end{tabular}

In order to investigate the effect of radiation on thermal properties of polymer, TGA (Thermal Gravimetric Analysis) and DTG (Differential Thermal Gravimetry) analyses were performed. Mass samples were about $10 \mathrm{mg}$.

Thermal analysis was carried out on a STA 449 Jupiter F1, Netzsch (Selb, Germany) under the following operation conditions: heating rate $10^{\circ} \mathrm{C} \mathrm{min}^{-1}$, dynamic atmosphere of helium $\left(40 \mathrm{~mL} \mathrm{~min}^{-1}\right)$ in the temperature range of $40-600^{\circ} \mathrm{C}$, sample weight of about $10 \mathrm{mg}$, sensor thermocouple of the S TG-DSC type.

All samples were subjected to thermogravimetric analysis, as a result of which it was possible to analyze the initial weight-loss temperature and decomposition temperatures. The analysis was performed in three ranges of mass loss: $0.01-0.05 \% \mathrm{w} / \mathrm{w}$ (Table 2), $0.1-0.5 \% \mathrm{w} / \mathrm{w}$ (Table 3) and 1-5\%w/w (Table 4). For comparison, unirradiated PMMAs (sample no. 4) are placed in the tables.

Table 2. Determination of weight loss temperature from $0.01 \mathrm{w} / \mathrm{w} \%$ to $0.05 \mathrm{w} / \mathrm{w} \%$.

\begin{tabular}{|l|l|l|l|l|l|}
\hline \multirow{2}{*}{$\begin{array}{l}\text { Sample } \\
\text { no. }\end{array}$} & \multicolumn{5}{|c|}{ Mass loss $[\% \mathrm{w} / \mathrm{w}]$ and temperature at which it occurs $\left[{ }^{\circ} \mathrm{C}\right]$} \\
\cline { 2 - 6 } & 0.01 & 0.02 & 0.03 & 0.04 & 0.05 \\
\hline
\end{tabular}




\begin{tabular}{|l|l|l|l|l|l|}
\hline 1 & 147.4 & 150.0 & 151.1 & 155.2 & 155.9 \\
\hline 2 & 33.5 & 33.6 & 33.7 & 33.8 & 33.9 \\
\hline 3 & 36.5 & 36.9 & 37.0 & 37.1 & 37.2 \\
\hline 4 & 110.0 & 113.1 & 115.1 & 118.3 & 120.0 \\
\hline
\end{tabular}

worth, in further studies, seeing how big the devastating impact of an even higher radiation dose is.

Table 4. Determination of weight loss temperature from $1 \mathrm{w} / \mathrm{w} \%$ to $5 \mathrm{w} / \mathrm{w} \%$.

\begin{tabular}{|l|l|l|l|l|l|l|}
\hline \multirow{2}{*}{$\begin{array}{l}\text { Sample } \\
\text { no. }\end{array}$} & \multicolumn{5}{|c|}{ Mass loss $[\% \mathrm{w} / \mathrm{w}]$ and temperatures at which it occurs $\left[{ }^{\circ} \mathrm{C}\right]$} \\
\cline { 2 - 7 } & 1 & 2 & 3 & 4 & 5 & $\mathrm{~T}_{\mathrm{I}}^{*}$ \\
\hline 1 & 277.0 & 286.6 & 290.7 & 294.1 & 297.0 & $0.6-258.3$ \\
\hline 2 & 194.4 & 305.9 & 316.8 & 322.2 & 325.7 & $1.2-262.9$ \\
\hline 3 & 202.4 & 295.6 & 308.1 & 317.7 & 323.8 & $1.2-264.9$ \\
\hline 4 & 225.0 & 300.0 & 313.0 & 320.0 & 325.0 & $1.27-268$ \\
\hline
\end{tabular}

Based on TGA analysis, it was found that the technical PMMA exposed to an X-ray dose of 243Gy (sample no. 1 ) is thermally stable to a temperature of about $150^{\circ} \mathrm{C}$. The mass loss in the range of $0.01-0.05 \% \mathrm{w} / \mathrm{w}$ takes place in the temperature range $147-160^{\circ} \mathrm{C}$ and is most likely related to the evaporation of unpolymerized MMA. It is also possible that depolymerization (for example PMMA dimers or trimers) takes place in this area. For samples no. 2 and no. 3, (the irradiated dose 419.7 and 493.1 respectively) it has been shown (Table 1) that this mass loss begins at much lower temperatures (about $34^{\circ} \mathrm{C}$ for sample no. 2 and $37^{\circ} \mathrm{C}$ for sample no. 3). Such a low temperature indicates most likely the devastating impact of X-rays. The same conclusions can be drawn based on the results obtained for the mass loss in the range of $0.1-$ $0.5 \% \mathrm{w} / \mathrm{w}$. Whereas for the sample no. 1 , the mass loss occurs at the temperature range $163.7-255.1^{\circ} \mathrm{C}$, for the sample no. 2 , this range is $34-70.1^{\circ} \mathrm{C}$ and for the sample no. 3 - $37.6-71.5^{\circ} \mathrm{C}$ (Table 2).

Table 3. Determination of weight loss temperature from $0.1 \mathrm{w} / \mathrm{w} \%$ to $0.5 \mathrm{w} / \mathrm{w} \%$.

\begin{tabular}{|l|l|l|l|l|l|}
\hline \multirow{2}{*}{$\begin{array}{l}\text { Sample } \\
\text { no. }\end{array}$} & \multicolumn{4}{|c|}{ Mass loss $[\% \mathrm{w} / \mathrm{w}]$ and temperatures at which it occurs $\left[{ }^{\circ} \mathrm{C}\right]$} \\
\cline { 2 - 6 } & 0.1 & 0.2 & 0.3 & 0.4 & 0.5 \\
\hline 1 & 163.7 & 181.9 & 197.9 & 222.1 & 255.1 \\
\hline 2 & 34.0 & 35.6 & 40.0 & 49.6 & 70.7 \\
\hline 3 & 37.6 & 38.6 & 42.0 & 46.8 & 71.5 \\
\hline 4 & 127.6 & 142.6 & 155.1 & 165.1 & 172.6 \\
\hline
\end{tabular}

In the last discussed range of mass loss, taking place in the area where proper decomposition of the sample occurs, better thermal resistance of the sample no. 1. can be clearly seen too.

It was also noted that a slight increase in the dose of radiation does not make much impact on thermal resistance of the sample. It can even be said that it has slightly improved it(sample number 3). Despite this, both for the sample no. 2 and no. 3, the initial devastating effects of radiation are significant and visible in all three discussed ranges of mass loss. For some measurement points, the sample no. 3 exhibits higher temperatures than the sample no 2 (difference several Celsius degrees). This may indicate that a larger radiation dose does not significantly affect the test samples. Nevertheless, it is

Particular attention should be paid to the fact that in all of these three ranges of mass loss, the sample no. 1 (irradiation dose 243Gy) showed a significantly higher heat resistance compared to the sample no. 4 (nonirradiated PMMA). Only in the area of the initial decomposition mass loss, the sample no. 4 exhibits greater temperature resistance compared to the sample no. 1 (Fig. 1).

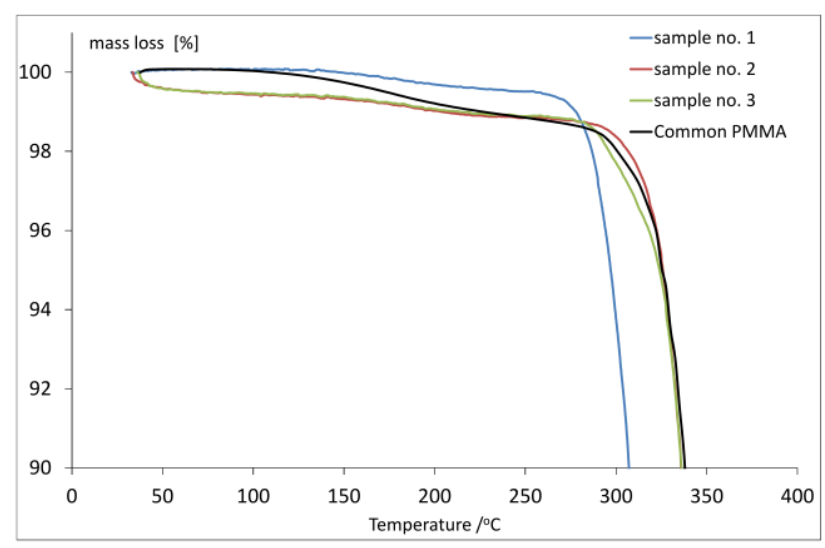

Fig. 1. TG - thermogravimetric analysis of irradiated and commercially available PMMA samples.

In conclusion, the results concerning a radiological impact on thermal properties of PMMA were presented in this study. Based on these results, it was found that a small dose of radiation (sample no. 1) improves the thermal properties of commercially available PMMA (sample no.4). A significant difference can be noticed when comparing the amount of mass loss at the initial decomposition temperature of the sample. In the case of the sample no. 1, $\mathrm{T}_{\mathrm{I}}$ is observed at a temperature of about $260^{\circ} \mathrm{C}$, but with only $0.6 \% \mathrm{w} / \mathrm{w}$ of mass loss. In contrast, the sample no. 4 (commercial PMMA) begins decomposition at a similar temperature but with twice the amount of mass loss. The reason for improving the 
thermal properties is probably the result of curing or crosslinking the polymer by radiation. The samples no. 2 and no. 3 (irradiated with a radiation dose 419.7Gy and 493.1Gy, respectively) show significantly lower thermal properties compared to the sample no. 1 and no. 4. On this basis, it can be concluded that higher radiation doses have destructive effects on the structure of PMMA, resulting in deterioration of their thermal properties.

\section{References}

[1] O. Ziemann et al., POF Handbook - Optical Short Range Transmission Systems (Springer, Berlin 2008).

[2] R.L. Clough, S.W. Shalaby, Radiation effects on polymers (American Chemical Society, Washington 1991).

[3] T. Coffey et al., J. Electron Spectroscopy and Related Phenom. 122, 65-78 (2002).

[4] T. Sasuga et al., Radiation Phys. and Chem. 37, 135-140 (1991).

[5] H. Henschel, M. Wittenburg, F. Wulf, Fiber Optic Radiation Sensing Systems for TESLA, TESLA Report, 2000-2026 (2000).

[6] H. Yoshida, T. Ichikawa, Radiation Phys. and Chem. 46, 921 (1995). 